\title{
Platelet Serotonin Concentration and Clinical Status in Alcohol Withdrawal Syndrome, Preliminary Results
}

\author{
Sergio G. Llinás MS, Antonio J. Caballero MD PhD, Julio C. Peñalver MD PhD, Rodolfo Valdés PhD
}

\begin{abstract}
INTRODUCTION Alcohol withdrawal syndrome is an important problem for management of alcoholism. It is known that alcohol alters the function of neurotransmitters such as serotonin, but our review found no studies associating serotonin concentration changes with patient clinical status during detoxification. The authors hypothesized that total platelet serotonin concentration should significantly increase during alcohol detoxification.
\end{abstract}

OBJECTIVE Assess possible association between total (endogenous and captured) platelet serotonin concentration and clinical status of patients with alcohol withdrawal syndrome, at beginning and end of detoxification with clomethiazole.

METHODS Thirty-one alcohol-dependent patients, diagnosed with alcohol withdrawal syndrome according to DSM-IV and classified in three clinical groups (18-20, 21-22 and 23-26 points) per the Clinical Institute Withdrawal Assessment for Alcohol Scale, were included in a prospective case series from May 2009 through May 2011 at the Hermanos Ameijeiras Clinical-Surgical Teaching Hospital in Cuba. Patients were predominantly male (87\%), ranging in age from 22 to 57 years; $40 \%$ were white, $40 \%$ mestizo and $20 \%$ black. All had been hospitalized for detoxification in the hospital's psychiatry service. Blood samples taken were mixed with $1 \%$ EDTA and centrifuged for

\section{INTRODUCTION}

Alcoholism has a great importance in psychiatry due to its increasing social impact. A primary chronic disease that is progressive and often fatal its manifestations are influenced by genetic, psychosocial, and environmental factors. It is characterized by impaired control over drinking, preoccupation with alcohol and an uncontrollable urge to drink despite adverse consequences.[1-3]

Reliable quantitative measures of alcohol intake and outcomes of alcoholic patients are needed to reduce the subjectivity of nonquantitative methods of classifying clinical status and monitoring response to treatment.[4] Serotonin's role in alcoholism and alcoholism withdrawal syndrome (AWS) may indicate potential usefulness as a biomarker of patient classification and progress.

Functions of some neurotransmitters such as serotonin (also known as 5-hydroxitriptamine or 5-HT), gamma-aminobutyric acid (GABA) and dopamine can be drastically modified under the effect of alcohol. The role of serotonin in alcoholism treatment has been studied for decades.[5,6] Alcoholics, who consume relatively larger quantities of alcohol, usually have lower brain serotonin than nonalcoholics. Chronic administration of ethanol reduces GABAergic neurotransmission by decreasing allosteric modulation of GABA receptors. $[7,8]$ It has been hypothesized that genetically determined low serotonin levels may be related to a predisposition to alcoholism.[9] On the other hand, low serotonin has also been implicated in depression, obsessive-compulsive disorders, anxiety, impulsiveness, aggression and suicide, all of which may coexist with alcoholism.[10] isolating platelets. Serotonin concentrations (endogenous and captured) were measured within 2 hours of blood collection and mean values at treatment days 1 and 12 compared by t test $(p<0.05)$.

RESULTS Total serotonin concentration mean values ( $\mu \mathrm{g}$ of serotonin per $\mathrm{mg}$ of total platelet protein) were statistically different between days 1 and 12 of treatment $(1.329 \pm 0.916 \mu \mathrm{g} / \mathrm{mg}$ vs. $2.573 \pm 1.224 \mu \mathrm{g} /$ $\mathrm{mg} ; \mathrm{p}<0.001$ ). There was a direct association between total serotonin concentration and patient clinical classification both initially and at day 12. At day 1 , the 29 patients in the group with $18-20$ points had mean serotonin of $1.358 \pm 0.0 .94 \mu \mathrm{g} / \mathrm{mg}$; one patient with 21 points had serotonin of $1.25 \mu \mathrm{g} / \mathrm{mg}$; and one patient with 24 points had serotonin of $0.740 \mu \mathrm{g} / \mathrm{mg}$. At day 12,26 patients had $0-1$ points, with mean serotonin $2.688 \pm 1.244 \mu \mathrm{g} / \mathrm{mg}$; and 5 patients had $2-8$ points, with mean serotonin $1.244 \pm 0.596 \mu \mathrm{g} / \mathrm{mg}$. No patient had >8 points at day 12 .

CONCLUSIONS Serotonin is a potential biomarker for initial clinical classification and outcome monitoring and could be useful to psychiatrists working with patients in this area of medical practice and research. Further studies including more patients and variables are necessary to support these preliminary results.

KEYWORDS Alcoholism, alcohol withdrawal syndrome, serotonin, biomarkers, Cuba
Serotonin may also contribute to alcohol intoxication and abnormalities in the brain's serotonin system, where it appears to play an important role in brain processes underlying alcohol abuse and dependence.[11] Moreover, acute and long term alcohol ingestion also affects serotonin receptors that convert the chemical signal produced by serotonin into functional changes in signal-receiving cells.[12]

Decreased serotonin in cerebrospinal fluid, serum, plasma, urine and platelets has also been observed in alcohol withdrawal syndrome (AWS),[5] a phenomenon of major clinical importance. $[13,14]$ Physical and psychological symptoms of AWS range from mild to severe and include nervousness, shakiness, anxiety, irritability or easy excitability, sudden emotional changes, headache, fatigue, nightmares, fuzzy thinking, fever, convulsion, blackouts, delirium tremens, involuntary eyelid movements, hand tremor, nausea, clammy or discolored skin, dilated pupils and rapid heart rate. $[15,16]$

Several drugs can be used to treat and prevent AWS symptoms; clomethiazole (also called chlormethiazole), originally developed in the 1930s, is still one of the most widely used. It is structurally related to thiamine (vitamin B1) and has sedative, hypnotic, muscle relaxant and anticonvulsant effects. It is also used for management of agitation, restlessness, short-term insomnia, and Parkinson disease in the elderly.[17,18] Clomethiazole acts as a positive allosteric modulator at the barbiturate/picrotoxin site of the GABA-A receptor. GABA is the major inhibitory neurotransmitter in the brain, and has anxiolytic, anticonvulsant, sedative and hypnotic effects. 
Clomethiazole's hypothermic and neuroprotective effects appear to be related to another mechanism; it regulates serotonergic transmission through its modulatory action on GABA.[19,20] Chemical transmission regulates approximately one third of brain impulses, including in the adrenergic and serotonergic systems involved in the neurobiological basis of anxiety disorders. In fact, it has been proposed that the anxiolytic action of benzodiazepines may result from inhibition of serotonin release in limbic structures.[21]

However, in our review of research over the past 30 years, we encountered no studies of AWS patients associating changes in serotonin concentration with clinical classification and outcomes; hence our interest in pursuing this line of research.

Platelets have been proposed as a peripheral source of serotonin because they share similarities with synaptosome in mechanisms of serotonin capture, storage and release; and also because of the presence of serotonin $2 \mathrm{~A}$ receptors in the cell membrane. The platelet serotonergic system has four main components: (i) the capture mechanism, (ii) intracellular storage organelles, (iii) serotonergic receptors in cytoplasmic membranes, and (iv) a mitochondrial enzyme for its metabolism. All these elements have physiological and pathophysiological similarities with the neuronal serotonergic system. In addition, serotonin capture by platelets occurs both actively and by passive diffusion. The active mechanism is mediated by a transporter protein similar to that of the neuronal active mechanism. There is also evidence that the serotonin transporter protein is encoded by the same gene in platelets and in the brain; and that the platelet carrier has the same functional and pharmacological characteristics as the neuronal transporter.[22-28] All of this makes platelets an appropriate model for studying neuronal serotonin.

Our research objective was to assess the possible association between serotonin concentration and both initial clinical classification and eventual outcome in patients treated for AWS with clomethiazole, by measuring total (endogenous and captured) platelet serotonin concentration.

\section{METHODS}

The Hermanos Ameijeiras Clinical-Surgical Teaching Hospital is a tertiary care hospital for adults located in Havana, Cuba; it has 625 beds, 15 medical and 12 surgical units, and 3 intensive care units.

Study type and population This preliminary prospective case series was carried out from May 2009 through May 2011. Alcohol-dependent patients included in the study were hospitalized in the psychiatry service (alcoholism consultation), with a history of heavy and prolonged alcohol consumption and recent interruption or reduction of alcohol. Thirty-one were admitted for a 15-day detoxification program, and the study was conducted during the first 12 days. Patients ranged in age from 22 to 57 years; 27 were male $(87 \%)$ and 4 female (13\%); $40 \%$ were white, $40 \%$ mestizo and $20 \%$ black.

Diagnosis Alcoholism was diagnosed per DSM-IV,[29] using the Schedules for Clinical Assessment in Neuropsychiatry.[30] The Clinical Institute Withdrawal Assessment for Alcohol Scale (CIWA-Ar) was administered by one of the authors (AJC) to diagnose AWS.[31] The interview covers signs and symptoms such as sweating, tachycardia, hand tremor, insomnia, nausea and/or vomiting, hallucinations, psychomotor agitation, anxiety and generalized tonic-clonic seizures. The CIWA-Ar range of possible scores is $0-30$, with higher scores indicating greater severity of withdrawal symptoms.

Patient inclusion criteria Age ranging 20 to 60 years old, signs and symptoms of AWS with CIWA-Ar score $\geq 18$ points.[31]

Patient exclusion criteria Use of other drugs that produce symptoms of anxiety during the month prior to the study; medical conditions (especially renal) that contraindicate treatment with clomethiazole; history of psychiatric illness (major depression, schizophrenia, epilepsy, bipolar disorder); moderate or profound mental retardation; and pregnancy or lactation.

Study variables These included platelet endogenous, captured and total serotonin concentration in micrograms per milligram total platelet protein; and AWS status per CIWA-Ar.

Clinical assessment Symptom assessment was always performed by two independent psychiatrists. AWS severity was classified per CIWA-Ar in four grades, from least to most severe: 1 (0-8 points), 2 (9-17 points), 3 (18-26 points), 4 (27-30 points). Additional subgroups were created to assess patients at the end of detoxification: $0-1,2-8$ and $>8$ points.

Treatment Patients were kept on a tryptophan-free diet and no vitamins were administered. All patients received oral clomethiazole on days 1 through 10 of the study, in decreasing doses according to the following scheme for number of 192-mg tablets per patient at breakfast, lunch and dinner:

Day 1: $\quad 2-2-4$ (total dose $1.54 \mathrm{~g}$ )

Days 2 and 3: 2-2-3 (total dose $1.34 \mathrm{~g}$ )

Days 4 and 5: $1-2-3$ (total dose $1.15 \mathrm{~g}$ )

Day 6: $\quad$ 1-2-2 (total dose $0.96 \mathrm{~g}$ )

Day 7: $\quad 1-1-2$ (total dose $0.77 \mathrm{~g}$ )

Day 8: $\quad 1-1-1$ (total dose $0.58 \mathrm{~g}$ )

Day 9: $\quad 1-0-1$ (total dose $0.38 \mathrm{~g}$ )

Day 10: $\quad$ 0-0-1 (total dose $0.19 \mathrm{~g}$ )

Laboratory procedures Early-morning blood samples were taken from fasting patients on days 1 (prior to first dose of chlomethiazole) and 12 of the treatment period; $10 \mathrm{~mL}$ of venous blood was drawn and transferred to a plastic tube containing $1 \mathrm{~mL}$ of $1 \%$ EDTA, then centrifuged at $800 \mathrm{~g}$ for $30 \mathrm{~min}$ to obtain platelet-rich plasma (PRP). PRP is stable at $4^{\circ} \mathrm{C}$ for several hours, but all tests were conducted within 2 hours of venipuncture.

Platelet protein The Lowry method was used to estimate total platelet protein.[32]

Endogenous serotonin One milliliter of PRP was centrifuged at $800 \mathrm{~g}$ for $20 \mathrm{~min}$; then plasma was discarded and the pellet washed twice with physiological saline $(0.9 \% \mathrm{NaCl})$. Platelets were resuspended in distilled water with $0.5 \mathrm{~mL}$ of perchloric acid $(0.4 \mathrm{~mol} / \mathrm{L})$ and shaken to promote platelet lysis. This material was then centrifuged again at $1500 \mathrm{~g}$ for $10 \mathrm{~min}$, and $2 \mathrm{~mL}$ of supernatant used to determine serotonin concentration with a reverse-phase high performance liquid chromatography (RPHPLC) C-18 column (Merck, Germany) with electrochemical detection (Knauer, Germany). Sample volume was $25 \mu \mathrm{L}$ and the column was operated at $1 \mathrm{~mL} / \mathrm{min} ; 0.1 \mathrm{~mol} / \mathrm{L}$ phosphate buffer 
was used as mobile phase; MW 387 (SIGMA-Aldrich, USA) was used as serotonin reference material.

Captured serotonin Serotonin capture by platelets was determined by calculating increase in intraplatelet serotonin content after incubation in a serotonin-rich medium. One milliliter of PRP was incubated for $10 \mathrm{~min}$ at $37^{\circ} \mathrm{C}$, and then again for $5 \mathrm{~min}$ with the addition of $1 \mathrm{mg}$ of serotonin. Incubation was stopped by adding $3 \mathrm{~mL}$ of cold $1 \%$ EDTA diluted in physiological saline. The tubes were centrifuged at $800 \mathrm{~g}$ for $15 \mathrm{~min}$ to obtain the platelet pellet and then $2 \mathrm{~mL}$ of supernatant were used to determine serotonin concentration, also using an RP-HPLC C18 column with electrochemical detection. The serotonin reference material used was the same for all measurements.

Total serotonin Total serotonin concentration estimation was done by summing platelet endogenous and captured serotonin concentrations.

Statistical analysis Statgraphic Centurion XV and Microsoft Excel software were used. After corroborating data variance normality and homogeneity by Kolmogorov-Smirnov and Cochran tests, a $t$ test for paired samples was used to assess significance of differences between values on days 1 and 12. A serotonin increase/ decrease factor was calculated for all individual serotonin concentrations (total, endogenous and captured) by dividing serotonin concentration at day 12 by serotonin concentration at day 1 ; means and standard deviations were calculated for groups and subgroups. A significance threshold of $p<0.05$ was used for all statistical tests.

Ethics The Hermanos Ameijeiras Clinical-Surgical Teaching Hospital research ethics committee approved the study design. Written informed consent to participate was obtained from patients, or from next of kin or legal guardians.

\section{RESULTS}

Table 1 shows mean and individual serotonin concentrations for patients with AWS on days 1 and 12 of detoxification. Total serotonin concentration is illustrated in Figure 1. Higher serotonin values were associated with lower scores, that is, better clinical status (Figures 1 and 2). At the beginning, total serotonin concentration values were as follows: for the group with 18-20 points (29 patients), $1.358 \pm 0.940 \mu \mathrm{g} / \mathrm{mg}$; $21-22$ points, (1 patient), $1.050 \mu \mathrm{g} /$ $\mathrm{mg}$; and $23-26$ points (1 patient), $0.740 \mu \mathrm{g} / \mathrm{mg}$. Similar associations between higher serotonin concentration and better clinical status were observed for endogenous and captured serotonin on day 1. No differences were observed between endogenous serotonin concentration values of the group with 18-20 points $(0.920 \pm 0.632 \mu \mathrm{g} / \mathrm{mg})$ and that with $21-22$ points $(1.0 \mu \mathrm{g} / \mathrm{mg})$. Differences among serotonin concentration values of these 3 classification groups at day 1 of the treatment were higher for captured serotonin concentration values; $18-20$ points, $0.429 \pm 0.0 .438 \mu \mathrm{g} /$ $\mathrm{mg} ; 21-22$ points, $0.050 \mu \mathrm{g} / \mathrm{mg}$; and $23-26$ points, $0.110 \mu \mathrm{g} / \mathrm{mg}$.

On day 12 , all 31 patients were in the group with 0-8 points. As on day 1 , there was a direct association between clinical status and total serotonin concentration. The same held for endogenous and captured serotonin concentrations: mean endogenous serotonin concentration for the 0-8-point group was $1.931 \pm \mu \mathrm{g} / \mathrm{kg}$; for the 0-1-point subgroup, $2.000 \pm 0.880 \mu \mathrm{g} / \mathrm{mL}$; and for the 2-8-point subgroup, $0.923 \pm 0.675 \mu \mathrm{g} / \mathrm{mg}$. Mean captured serotonin concentration for the $0-8$-point group was $0.673 \pm 0.671 \mu \mathrm{g} / \mathrm{mg}$; for the subgroup with $0-1$ points, $0.675 \pm 0.718 \mu \mathrm{g} / \mathrm{mg}$; and $0.467 \pm 0.207$ $\mu \mathrm{g} / \mathrm{mg}$ for the subgroup with 2-8 points.

Mean endogenous serotonin concentration doubled between day 1 and day 12 , from $0.922 \pm 0.613 \mu \mathrm{g} / \mathrm{mg}$ to $1.899 \pm 0.884 \mu \mathrm{g} / \mathrm{mg}$ at day 12 ( $p<0.001)$. Mean values of captured serotonin concentration were $0.407 \pm 0.433 \mu \mathrm{g} / \mathrm{mg}$ (day 1) and $0.674 \pm 0.664 \mu \mathrm{g} / \mathrm{mg}$ (day 12), corresponding with an increase of 1.6 times. These values also showed statistical differences $(p=0.045)$. Consequently, endogenous serotonin concentration was always higher than captured serotonin concentration in both days ( 2.3 times at day 1 and 2.8 times at day 12). Mean total serotonin almost doubled, and significantly, between day 1 and day $12(1.329 \pm 0.916 \mu \mathrm{g} / \mathrm{mg}$ and $2.573 \pm 1.226 \mu \mathrm{g} / \mathrm{mg}$ respectively; $p<0.001$ ) (Table 1 ).

These differences are reflected in the total serotonin increase factors by clinical groups: 1.9 for those initially classified at 18-20 points, 2.7 for those with 21-22 points, and 1.9 for those with 23-24 points. In the subgroups with $0-1$ and $2-8$ points on day 12 , mean total serotonin concentration increased by factors of 1.8 and 2.7 , respectively.

However, serotonin concentration values dropped at day 12 in some patients. In patient 9 , endogenous concentration decreased from 1.220 to $1.070 \mu \mathrm{g} / \mathrm{mg}$, but total serotonin concentration increased from 1.770 to $2.170 \mu \mathrm{g} / \mathrm{mg}$. In patient 14 , endogenous serotonin decreased from 1.470 to $1.060 \mu \mathrm{g} / \mathrm{mg}$. A similar phenomenon was observed for captured serotonin concentration in

Table 1: Alcohol withdrawal syndrome status and serotonin concentration

\begin{tabular}{|c|c|c|c|c|c|c|c|c|c|c|}
\hline Day & $\begin{array}{l}\text { Clinical } \\
\text { Group }\end{array}$ & $\begin{array}{l}\text { Clinical } \\
\text { Subgroup }\end{array}$ & $\begin{array}{c}\text { Patient } \\
\text { n }\end{array}$ & $\begin{array}{l}\text { Endogenous } \\
\text { serotonin } \\
(\mu \mathrm{g} / \mathrm{mg}) \\
\text { Day } 1\end{array}$ & $\begin{array}{l}\text { Endogenous } \\
\text { serotonin } \\
\text { ( } \mathrm{gg} / \mathrm{mg}) \\
\text { Day } 12\end{array}$ & $\begin{array}{c}\text { Captured } \\
\text { serotonin } \\
\text { ( } \mu \mathrm{g} / \mathrm{mg}) \\
\text { Day } 1\end{array}$ & $\begin{array}{c}\text { Captured } \\
\text { serotonin } \\
(\mu \mathrm{g} / \mathrm{mg}) \\
\text { Day } 12\end{array}$ & $\begin{array}{c}\text { Total } \\
\text { serotonin } \\
\text { ( } \mathrm{gg} / \mathrm{mg}) \\
\text { Day } 1\end{array}$ & $\begin{array}{c}\text { Total } \\
\text { serotonin } \\
(\mu \mathrm{g} / \mathrm{mg}) \\
\text { Day } 12\end{array}$ & $\begin{array}{c}\text { Total } \\
\text { serotonin } \\
\text { increase } \\
\text { factor } \\
\text { Day } 12\end{array}$ \\
\hline \multirow{2}{*}{12} & & $0-1$ & 26 & & $2.000 \pm 0.880$ & & $0.675 \pm 0.718$ & & $2.688 \pm 1.244$ & 1.823 \\
\hline & & $2-8$ & 5 & & $0.923 \pm 0.675$ & & $0.467 \pm 0.207$ & & $1.244 \pm 0.596$ & 2.174 \\
\hline 12 & $9-17$ & & 0 & & & & & & & \\
\hline 1 & & $21-22$ & 1 & 1.000 & & 0.050 & & 1.474 & & \\
\hline 1 & & $23-26$ & 1 & 0.630 & & 0.110 & & 0.572 & & \\
\hline 1 & $27-33$ & & 0 & & & & & & - & - \\
\hline Mean $\pm S D$ & & & 31 & $0.922 \pm 0.613$ & $1.899 \pm 0.884$ & $0.407 \pm 0.433$ & $0.672 \pm 0.663$ & $1.329 \pm 0.916$ & $2.570 \pm 1.226$ & 1.936 \\
\hline p Value & & & 0 & & .001 & & 45 & $<0$ & 01 & \\
\hline
\end{tabular}


patients 13 (from 1.536 to $1.400 \mu \mathrm{g} / \mathrm{mg}$ ), 14 (0.610 to $0.470 \mu \mathrm{g} /$ $\mathrm{mg}), 17(0.811$ to $0.183 \mu \mathrm{g} / \mathrm{mg})$ and $25(2.000$ to $0.860 \mu \mathrm{g} / \mathrm{mg})$. Total serotonin concentration was lower on day 12 for patients 13 , 14, 17 and 25 (Figure 1).

Finally, Table 1 and Figure 2 show values of patient clinical status assessment per CIWA-Ar. Mean scores decreased after treatment, from $18.74 \pm 1.33$ points at day 1 to $0.77 \pm 2.29$ points at day 12 . This decrease coincided with a statistically significant increase in mean endogenous, captured and total serotonin concentrations from day
1 to day 12 (2.05, 1.43 and 1.93 times, respectively). On day 1 all patients were evaluated as grade $3(18-20,21-22,23-26$ points) per CIWA-Ar clinical symptoms. Of these, 93.6\% (29/31) registered 18-20 points, with one each in the groups registering 21-22 and 23-26 points. At day 12, an important improvement in the patients' clinical status was observed; $26(83.9 \%)$ patients had no symptoms, for a score of $0 ; 4(12.9 \%)$ had 2 points and one had 8 points (3.2\%). Mean total serotonin concentrations were $2.688 \pm 1.244 \mu \mathrm{g} /$ $\mathrm{mg}$ for those with $0-1$ points, $2.058 \pm 0.195$ for 2 points and 0.779 $\mu \mathrm{g} / \mathrm{mg}$ for 8 points, showing a direct association with clinical status.
Figure 1: Total serotonin concentration in Alcohol withdrawal syndrome patients days 1 and 12 of detoxification $(n=31)$

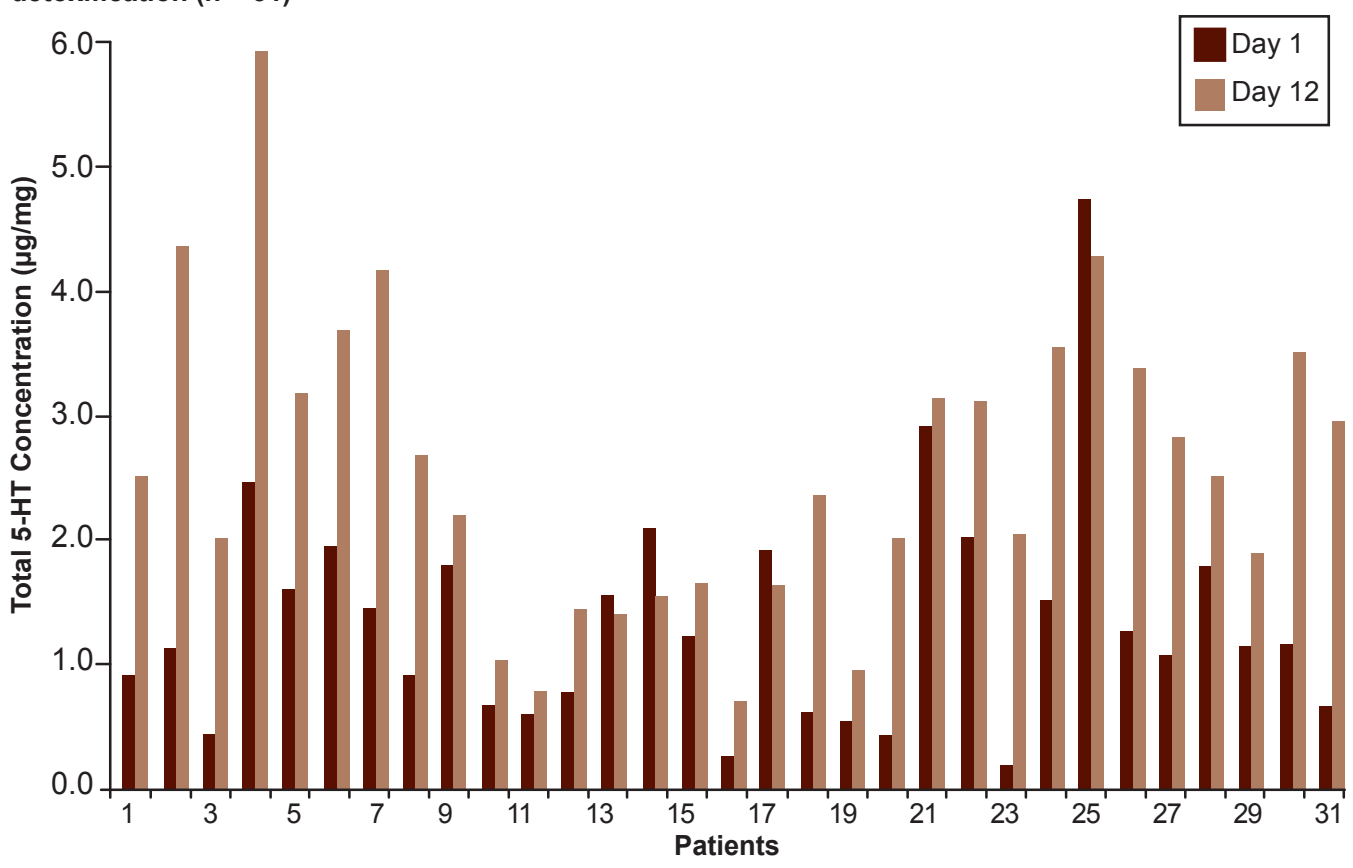

Figure 2: Alcohol withdrawal syndrome* patient clinical status days 1 and 12 of detoxification $(n=31)$

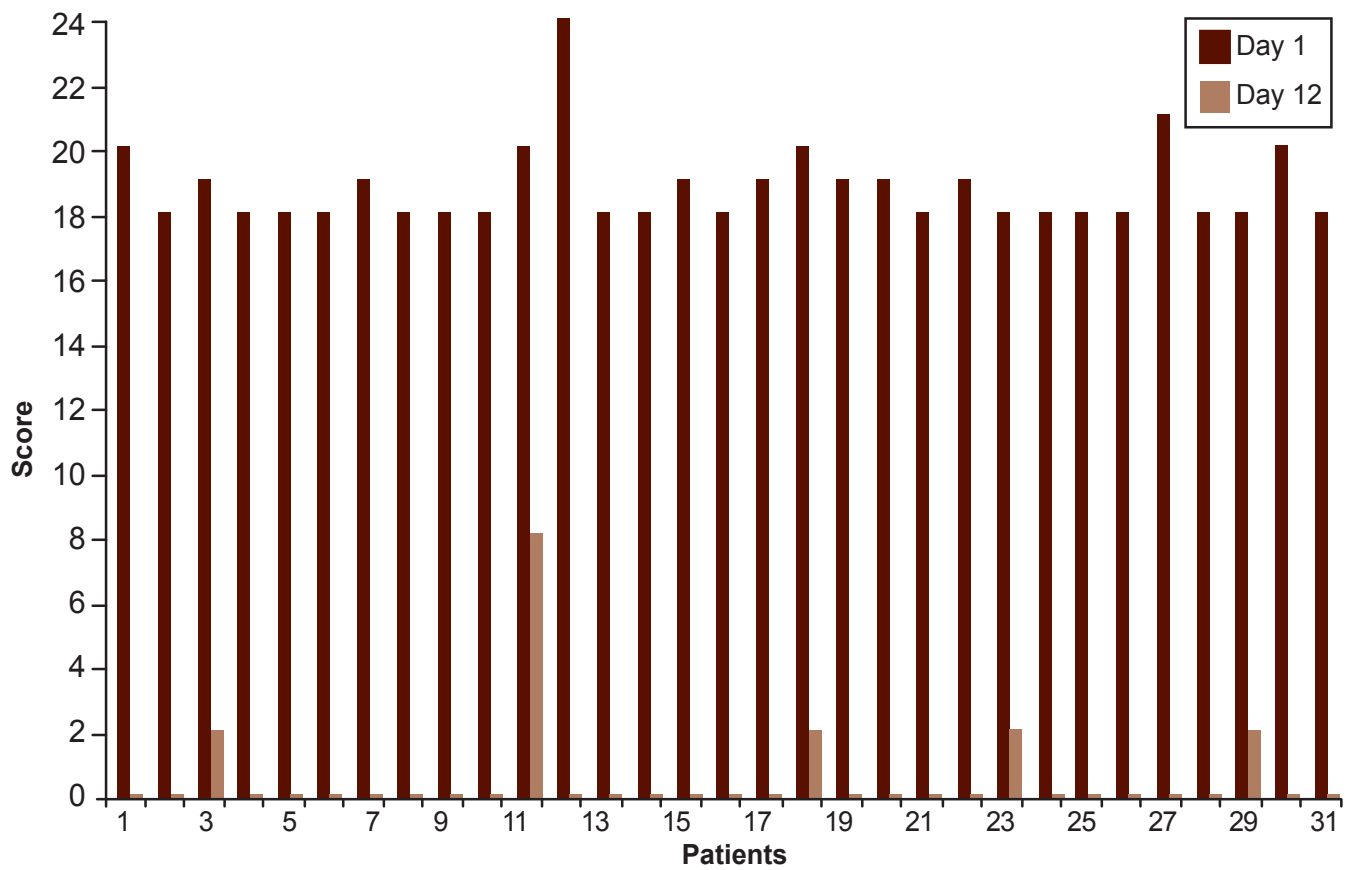

\section{DISCUSSION}

Knowing that alcohol alters serotonin structure and function,[5] we hypothesized that serotonin concentration might be a potential biological marker for initial classification of clinical status and for assessing progress in AWS patients treated with clomethiazole. In fact, we did find a direct association between clinical status and total serotonin concentration in most patients studied.

Other researchers have also reported changes in serotonin concentration in patients during the withdrawal period, but these studies found similar serotonin concentrations in control groups and, in contrast to our findings, serotonin levels declined and remained lower than controls' even after 14 days of abstinence. [7-9] However, those patients were receiving benzodiazepines, which may suppress serotonin activity.[10] In addition, the day of admission may not have been the actual beginning of withdrawal for all patients. Finally, all subjects were Caucasian men, limiting generalizability. None of our patients received benzodiazepines and admission day corresponded with the beginning of the withdrawal period, confirmed by daily application of the patient evaluation scale. We intend to publish a further study using benzodiazepines.

It should be noted that there is no evidence suggesting a direct effect of clomethiazole on serotonin-its efficacy in AWS is related to the GABA-A mechanism previously described-so it cannot be assumed that changes in serotonin concentration observed in this study are due to the drug. 
Interestingly, in the four patients whose serotonin concentrations decreased over the study period, this was due to a fall in captured serotonin concentration. Among these, patient 14's endogenous serotonin also failed to increase. Further study is needed to understand the paradox of decreased captured serotonin in the presence of palpable clinical improvement.

All four of these patients were within the clinical subgroup of $0-1$ points on day 12 , that is, with virtually no clinical signs of AWS; interestingly, they reported depressive episodes during the detoxification period, which could explain the lack of serotonin increase. Other authors have demonstrated that decreased brain serotonin is the core pathogenic factor in depression (a heterogeneous disease with diverse pathogenesis), pursuant to clinical observations that drugs enhancing extracellular or captured levels of serotonin have antidepressant effects in many patients.[23]

Better AWS clinical status (assessed by two independent psychiatrists) was positively associated with total serotonin concentration on the first day of detoxification. From this preliminary evidence, we conclude that total serotonin concentration might be used as a biomarker to validate clinical classification at initiation of AWS treatment. Furthermore, the positive association between total serotonin concentration and clinical improvement following detoxification suggests that it could also be used to monitor clinical status during and after detoxification.

Nevertheless, the apparent contradictory results for patient 11 cannot be ignored: this patient showed a significant increase in total serotonin concentration at the end of detoxification but not total recovery from AWS symptoms. In this case, endogenous serotonin concentration was unmodified. Although conclusions cannot be drawn from results of a single patient, this might suggest a stronger specific role for endogenous serotonin.

As expected, all patients experienced AWS symptoms upon alcohol cessation and improved by study end. Another result, that of a patient who improved substantially but still had several symptoms at the end of the study, warrants further study. Differing alcohol use patterns, genetically determined differences in the nervous system, sex, age, or possible depression during detoxification could also contribute to this variability in treatment response.

Trevisan reported that about $10 \%$ of AWS patients have serious symptoms (including delirium tremens, which has a mortality rate of $5-25 \%$ ).[33] Ruusa concluded that testosterone levels influence AWS symptoms, observing that patients with low testosterone levels develop more neurotic-asthenic symptoms during alcohol withdrawal; that high levels of sex hormones are related to a history of seizures; and that younger alcoholics score higher on the paranoid-aggressive subscale of the comprehensive psychopathological rating scale.[34]

This study must be considered preliminary because of its small sample size and lack of a control group; in addition, a number of potentially important variables could not be assessed. Accumulating a sample size adequate to take into consideration varying symptomatology, alcohol use history, genetic predisposition, sex, diet, medication use and clinical status at baseline is a serious challenge for this sort of research, and probably can only be done in a multicenter study.

\section{CONCLUSIONS}

This study provides preliminary evidence of a positive association between increased total platelet serotonin and clinical status in AWS patients treated with clomethiazole, making serotonin a candidate biomarker for monitoring and studying AWS. If validated, it could also be used in studies of other psychiatric disorders, such as depression, psychosis and anxiety. Nevertheless, larger studies able to address more variables are needed to confirm these results.

\section{ACKNOWLEDGMENTS}

The authors thank members of the Hermanos Ameijeiras ClinicalSurgical Teaching Hospital Department of Psychiatry and its pharmacokinetics laboratory where this study was conducted. Thanks also to Williams Ferro MS for assistance, Ministry of Public Health for research support, and to the patients for their voluntary contribution to science. $-1 /$ -

\section{REFERENCES}

1. World Health Organization. Global status report on non-communicable diseases [Internet]. Geneva: World Health Organization; 2010 [cited 2013 Sep 26]. 164 p. Available from: http://www.who .int/nmh/publications/ncd_report_full_en.pdf

2. Sánchez JF, Álvarez P, Rodríguez JJ. Psychiatric disorders associated with alcoholism: 2 year follow-up of treatment. Actas Esp Psiquiatr. 2012 May-Jun;40(3):129-35.

3. Chen CY, Storr CL, Anthony JC. Early-onset drug use and risk for drug dependence problems. Addict Behav. 2009 Mar;34(3):319-22.

4. Freeman WM, Vrana KE. Future prospect for biomarkers of alcohol consumption and alcoholinduced disorder. Acohol Clin Exp Res. 2010 Jun;34(6):946-54.

5. Johnson BA. Role of serotoninergic system in the neurobiology of alcoholism. CNS Drugs. 2004;18(15):1105-18.

6. Berger M, Gray JA, Roth BL. The expanded biology of serotonin. Ann Rev Med. 2009;60:355-66.

7. Aguayo LG, Peoples RW, Yeh HH, Yevenes GE. GABA $(A)$ receptors as molecular sites of ethanol action. Direct or indirect actions? Curr Top Med Chem. 2002 Aug;2(8):869-85.

8. Bajo M, Madamba SG, Lu X, Sharkey LM, Bartfai $T$, Siggins GR. Receptor subtype-dependent galanin actions on $\mathrm{Y}$-aminobutyric acidergic neurotransmission and ethanol responses in the central amygdala. Addict Biol. 2012 Jul;17(4):694-705.

9. Schuckit MA. Alcohol-use disorders. Lancet. 2009 Feb 7;373(9662):492-501.

10. Nenadic-Sviglin K, Nedic G, Nikolac M, Kozaric-Kovacic D, Stipcevic T, Muck Seler D, et al. Suicide attempt, smoking, comorbid depression, and platelet serotonin in alcohol dependence. Alcohol. 2011 May;45(3):209-16.

11. Mukherjee S, Das SK, Vaidyanathan K, Vasudevan DM. Consequences of alcohol consumption on neurotransmitters-An overview. Curr Neurovasc Res. 2008 Nov;5(4):266-72

12. Lovinger DM. The role of serotonin in alcohol's effects on the brain. Curr Separations. 1999;18(1):23-8.

13. Hughes JR. Alcohol withdrawal seizures. Epilepsy Behav. 2009 Jun;15(2):92-7.
14. Martín MM, Pastor I, Laso F. Farmacogenética en el tratamiento del alcoholismo. Act Farmacol Terapéutica. 2012;10(3):159-60. Spanish.

15. Bayard M, Mclntyre J, Hill KR, Woodside JJr. Alcohol withdrawal syndrome. Am Fam Physician. 2004 Mar;69(6):1443-50.

16. Veray R, Vekaria S, Eisenberg S. Treatment of the hospitalized alcohol-dependent patient with alcohol withdrawal syndrome. Internet J Int Med [Internet]. 2009 [cited 2013 Sep 26];8(1). Available from: http://ispub.com/lJIM/8/1/6232\#

17. Reilly TM. Physiological dependence on, and symptoms of withdrawal from chlormethiazole. Brit J Psychiatry. 1976 Apr;128:375-8.

18. Kleber HD, Weiss RD, Anton RF Jr, George TP, Greenfield SF, Kosten TR, et al. Treatment of patients with substance use disorders, second edition. American Psychiatric Association. Am J Psychiatry. 2007 Apr;164(4 Suppl):5-123.

19. Cortes C, Galindo F, Galicia S, Flores A. GABA: ¿dualidad funcional? Transición durante el neurodesarrollo. Rev Neurol. 2011 Jun;52(11):66575. Spanish 


\title{
Original Research
}

20. Möhler H. GABAA receptor diversity and pharmacology. Cell Tissue Res. 2006 Nov;326(2):505-16.

21. Paton C. Benzodiazepines and disinhibition: a review. The Psychiatrist. 2002;26:460-2.

22. Lesch KP, Wolozin BL, Murphy DL, Reiderer P. Primary structure of the human platelet serotonin uptake site: identity with the brain serotonin transporter. J Neurochem. 1993 Jun;60(6):2319-22.

23. Sneddon JM. Blood platelets as a model for monoamine-containing neurones. Prog Neurobiol. 1973;1(2):151-98

24. Javors $M$, Tiouririne M, Prihoda T. Platelet serotonin uptake is higher in early-onset than in late-onset alcoholics. Alcohol Alcohol. $2000 \mathrm{Jul}-$ Aug;35(4):390-3

25. Arranz B, Rosel P, Sarró S, Zaldivar E, Cano R, Navarro MA, et al. Platelet serotonergic binding sites in alcohol-dependent patients. Alcohol Alcohol. 1999 Sep-Oct;34(5):726-32.

26. Bailly D, Vignau J, Racadot N, Beuscart R, Servant $D$, Parquet PJ. Platelet serotonin levels in alcoholic patients: changes related to physiological and pathological factors. Psychiatry Res. 1993 Apr;47(1):57-88.

27. Bailly D, Vignau J, Lauth B, Racadot N, Beuscart $R$, Servant $D$, et al. Platelet serotonin decrease in alcoholic patients. Acta Psychiatr Scand. 1990 Jan;81(1):68-72.

28. Alvarez JC, Gluck N, Arnulf I, Quintin P, Leboyer $\mathrm{M}$, Pecquery $\mathrm{R}$, et al. Decreased platelet serotonin transporter sites and increased platelet inositol triphosphate levels in patients with unipolar depression: effects of clomipramine and fluoxetine. Clin Pharmacol Ther. 1999 Dec;66(6):617-24

29. American Psychiatric Association. Diagnostic and Statistical Manual of Mental Disorders. DSMIV.4th ed. Washington: American Psychiatric Association; 2001

30. Easton C, Meza E, Mager D, Ulüg B, Kilic C Gögüs $A$, et al. Test-retest reliability of the schedules for clinical assessment in neuropsychiatry (SCAN). Drug Alcohol Depend. 1997 Sep 25:47(3):187-94

31. Sullivan JT, Sykora K, Schneiderman J, Naranjo CA, Sellers EM. Assessment of alcohol withdrawal: the revised clinical institute withdrawal assessment for alcohol scale (CIWA-Ar). $\mathrm{Br} J$ Addict. 1989 Nov;84(11):1353-7.

32. Lowry $\mathrm{OH}$, Rosenbrough NJ, Farr AL, Randall RJ. Protein measurement with the Folin phenol reagent. J Biol Chem. 1951 Nov;193(1):265-75.

33. Trevisan L, Boutros N, Petrakis IL, Krystal JH. Complications of alcohol withdrawal, pathophysiological insights. Alcohol Health \& Res World. 1998;22(1):61-6.

34. Ruusa J, Bergman B. Sex hormones and alcohol withdrawal: does a good supply of testosterone prevent serious symptoms during detoxification? Alcohol. 1996 Mar-Apr;13(2):139-45.

\section{THE AUTHORS}

Sergio G. Llinás Carrillo, pharmacologist, Hermanos Ameijeiras Clinical-Surgical Teaching Hospital, Havana, Cuba.

Antonio J. Caballero Moreno, psychiatrist, Galigarcía Psychiatric Center, Enrique Cabrera General Teaching Hospital. Havana, Cuba.

Julio C. Peñalver González, physician with a doctorate in neurophysiology. Santa Fe University Hospital, Valencia, Spain.

Rodolfo Valdés Véliz (Corresponding author: rodolfo.valdes@cigb.edu.cu), biologist with a doctorate in biochemistry. Center for Genetic Engineering and Biotechnology, Havana, Cuba.

\section{Submitted: May 19, 2013}

Approved for publication: January 15, 2014

Disclosures: None

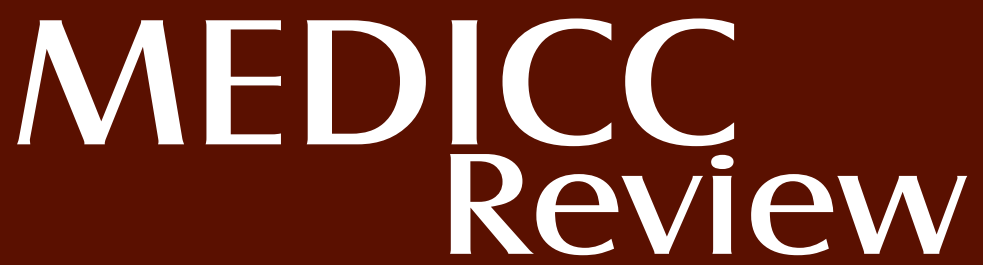

Themes for Upcoming Issues

\section{4 - 2015 $\vdots$ The Mystery of Chronic Kidney Disease (CKDu)}

\author{
Genetics \& Population Health
}

Cancer

Maternal \& Child Health

Environment, Climate Change \& Health

...and in every issue

- Original research by Cuban and international medical scientists and health professionals

- Exclusive features and interviews

- Viewpoints on hot topics in medicine and health in Cuba and the world 